\title{
Pleomorphic adenoma of the larynx
}

\author{
Meryem Doğan Altunpulluk, ${ }^{1}$ Murat Hakan Karabulut, ${ }^{1}$ Gözde Kır ${ }^{1}$ Şamil Şahin ${ }^{2}$ \\ ${ }^{1}$ Department of Pathology, Umraniye Education and Research Hospital, Istanbul, Turkey \\ 2Department of Otolaryngology Umraniye Education and Research Hospital, Istanbul, Turkey
}

\begin{abstract}
Pleomorphic adenoma (PA) is the most common benign neoplasm of the salivary glands. It usually occurs in major salivary glands, such as the parotid and submandibular glands. Occasionally, however, it occurs in the larynx. These lesions generally present as a slow-growing, painless mass. Malignant transformation is very rare, but it increases with time. The present report is the case of a 59-year-old male who presented with a complaint of hoarseness. Right vertical partial hemilaryngectomy revealed an intact, mucosa-covered, fleshy $2 \times 1.5 \times 1 \mathrm{~cm}$ mass in the supraglottic area of the larynx. Lesion had histological characteristics of a PA, and this was confirmed by immunohistochemical expression of cytokeratin, S100 protein, Glial fibrillary acidic protein (GFAP) and vimentin. Their histopathological identification is, however, not always straightforward; immunohistochemistry can contribute significantly to formulation of a definitive diagnosis and to the realization of appropriate follow-up.
\end{abstract}

Keywords: Immunohistochemistry; larynx; pleomorphic adenoma.

$\mathrm{P}$ leomorphic adenoma (PA) is the most common salivary gland tumor and accounts for $60 \%$ of all salivary gland neoplasms [1]. About $80 \%$ of PAs arise in the parotid gland, $10 \%$ in the submandibular gland, and $10 \%$ in the minor salivary glands of the oral cavity, paranasal sinuses, and upper respiratory and alimentary tract [2].

Histologically, these tumors are encapsulated and consist of epithelial (or myoepithelial) and stromal elements. Epithelial component may form a variety of structures, including tubules, ductules, or trabeculae, and the stromal component may also consist of a variety of forms, including mucoid, myxoid, cartilaginous, and osseous elements. PAs may also occur at other sites, including the breast and skin (chondroid syringoma). It is rarely found in the larynx [3].

This report presents a case of PA in the larynx with characteristic pathologic and clinical findings as a reminder of a common benign neoplasm occurring with rare locality.

\section{CASE REPORT}

A male patient aged 59 had a history of hoarseness. A right vertical hemilaryngectomy was performed. Tum or consisted of a firm, well-circumscribed, 

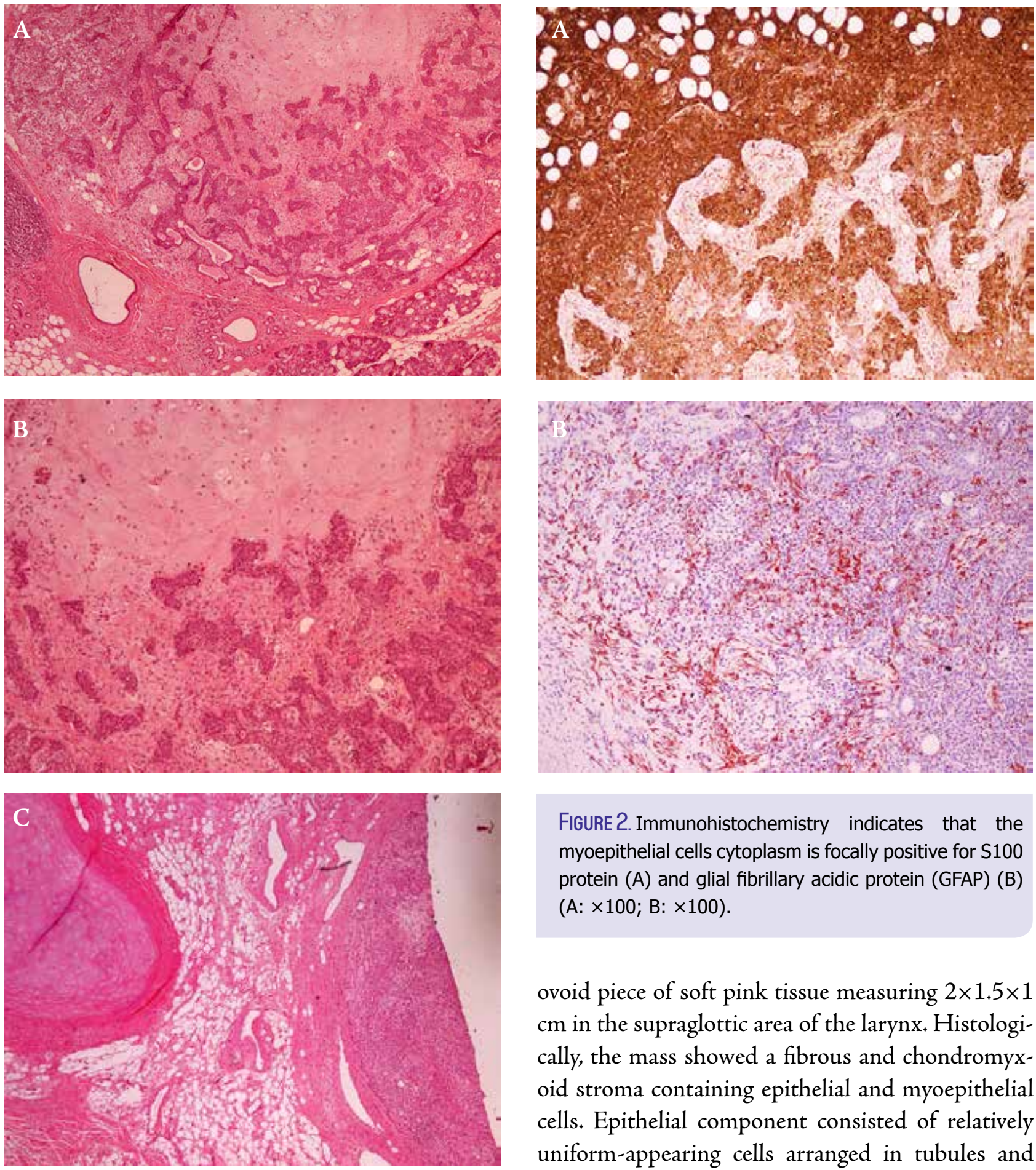

FIGURE2. Immunohistochemistry indicates that the myoepithelial cells cytoplasm is focally positive for $\mathrm{S} 100$ protein (A) and glial fibrillary acidic protein (GFAP) (B) $(A: \times 100 ; B: \times 100)$.

ovoid piece of soft pink tissue measuring $2 \times 1.5 \times 1$ $\mathrm{cm}$ in the supraglottic area of the larynx. Histologically, the mass showed a fibrous and chondromyxoid stroma containing epithelial and myoepithelial cells. Epithelial component consisted of relatively uniform-appearing cells arranged in tubules and small, nested aggregates (Figure 1). Results of immunohistochemical staining were consistent with

FIGURE 1. (A-B) Hematoxylin and eosin (H\&E) stained section showing sheets of myoepithelial cells and ductular structures lined with epithelial cells set in chondromyxoid stroma (H\&E, A: ×40; B: ×100). (C) Adjacent to the lesion, normal laryngeal cartilage can be seen $(H \& E, \times 100)$. PA. The epithelial component showed positivity for cytokeratin. Myoepithelial component was positive for p63, S100 protein (Figure 2A), and glial fibrillary acidic protein (GFAP) (Figure $2 \mathrm{~B}$ ); and focally positive smooth muscle actin (SMA). 


\section{DISCUSSION}

PA is a commonly diagnosed benign tumor in the salivary glands that may also occur in a variety of other sites; however, it is rarely seen in the larynx. The diagnosis of PA is simple, but when it grows in an unusual site like the larynx, it can be mistaken for a malignant neoplasm.

PAs are usually slow-growing, solitary, painless tumors. Histopathological confirmation is mandatory for these tumors. Pleomorphic adenomas are characterized by epithelial tissue mixed with tissues of myxoid, mucoid or chondroid appearance. Histologically, pleomorphic adenoma of the larynx may resemble aggressive epithelial tumors because of the high cellularity and lack of a stromal component. Importantly, this feature is not in keeping with that of major salivary glands, which demonstrate relatively reduced myoepithelial cellularity. Occasionally, pleomorphic adenomas are composed almost entirely of epithelial cells with few or no stromata. This can lead to misdiagnosis as carcinoma [4]. Immunohistochemically, the inner ductal cells are positive for cytokeratin. Myoepithelial cells are variably positive for S100 protein, SMA, GFAP, calponin, and CD10 [5].

Although PA is a benign tumor, it can cause problems in clinical management due to its tendency to recur and risk of malignant transformation. Histological features indicative of malignant transformation include cytological atypia, increased mitotic figures, satellite tumor nodules, tumor necrosis, and infiltrative margins7. PAs have tendency to recur when not widely excised, particularly if they are predominantly mucoid [6], and have variability in the thickness of the capsule and the tumor invading the capsule [7]. In addition, due to low biological requirements, the neoplastic cells can survive when spilt into the operative sites [5].

PAs should be differentially diagnosed from other tumors such as carcinoma ex pleomorphic adenoma, adenoid cystic carcinoma, basal cell carcinoma, basal cell adenoma, myoepithelioma, polymorphous low-grade adenocarcinoma, angiofibroma, hamartoma, epidermoid cyst, hemangioma, vascular malformations, nasopharyngeal carcinoma, and nonepithelial tumors.
Carcinoma ex pleomorphic adenoma exhibits extensively infiltrative malignancy with necrosis, perineurial invasion, frequent mitotic figures, marked nuclear atypia. Adenoid cystic carcinoma usually shows cribriform, solid or tubular pattern similar to cylindromas of the skin. It is composed of small, bland myoepithelial cells with scant cytoplasm and dark, compact, angular nuclei that surround pseudoglandular spaces with periodic-acid Schiff (PAS)-positive excess basement membrane material and mucin. Peripheral perineurial invasion and small, true, glandular lumina are sometimes seen, but no squamous differentiation, and extensive necrosis is usually absent. Adenoid cystic carcinoma has high proliferative index, high $\mathrm{p} 53$ immunoreactivity, and intense staining for B-cell lymphoma 2 (BCL 2), but negative reactivity for glial fibrillary acidic protein. In contrast, pleomorphic adenoma is not invasive, shows no perineurial invasion and has squamous metaplasia and mesenchyme-like areas. Characteristically, pleomorphic adenoma has strong glial fibrillary acidic protein in the myxochondromatous areas [8]. Basal cell carcinoma is a lowgrade malignancy similar to basal cell adenoma. It is an infiltrative tumor with perineurial invasion and vascular invasion as well as variable cytologic atypia and mitotic activity. It is composed of solid, trabecular, tubular or membranous patterns, but no myxoid matrix or cartilagenous areas. Basal cell adenoma is composed of basaloid cells sharply delineated from the stroma by basement membrane. Polymorphous low-grade adenocarcinoma is usually a nonencapsulated tumor with diverse (polymorphous) growth patterns, infiltrative borders, perineurial invasion and tumor necrosis is rare $[9,10]$. Differential diagnosis of PA consists of myoepithelioma, a benign epithelial salivary gland tumor, and presence of plasmacytoid or spindled myoepithelial cells. Additionally, basal cell adenoma may also be involved in the differential diagnosis [11].

To conclude, pleomorphic adenoma of the larynx is a rare neoplasm and therefore its diagnosis requires a high index of suspicion. Complete wide surgical excision is the treatment of choice. Recurrence many years after surgical excision as well as malignant transformation should be a concern and 
therefore long-term follow-up is necessary.

Conflict of Interest: No conflict of interest was declared by the authors.

Financial Disclosure: The authors declared that this study has received no financial support.

Authorship contributions: Concept - M.D.A; Design M.D.A; Data collection and/or processing - M.H.K.; Analysis and/or interpretation - M.D.A; Literature search - M.D.A.; Writing - M.D.A; Critical review - G.K., M.H.K.

\section{REFERENCES}

1. Spiro RH. Salivary neoplasms: overview of a 35-year experience with 2,807 patients. Head Neck Surg 1986;8:177-84. Crossref

2. Eveson JW, Cawson RA. Salivary gland tumours. A review of 2410 cases with particular reference to histological types, site, age and sex distribution. J Pathol 1985;146:51-8. Crossref

3. Ordóñez NG, Manning JT, Luna MA. Mixed tumor of the vulva: a report of two cases probably arising in Bartholin's gland. Cancer 1981;48:181-6. Crossref

4. Compagno J, Wong RT. Intranasal mixed tumors (pleomorphic adenomas): a clinicopathologic study of 40 cases. Am J Clin Pathol 1977;68:213-8. Crossref

5. Eveson JW, Kusafuka K, Stenman G, Nagao T. Pleomorphic adenoma. In: Barnes L, Eveson JW, Reichart P, Sidransky D, editors. Pathology \& Genetics, Head and Neck Tumours. 1st ed. Lyon: IARC Press; 2005. p. 254-9.

6. Renehan A, Gleave EN, Hancock BD, Smith P, McGurk M. Long-term follow-up of over 1000 patients with salivary gland tumours treated in a single centre. Br J Surg 1996;83:1750-4.

7. Henriksson G, Westrin KM, Carlsöö B, Silfverswärd C. Recurrent primary pleomorphic adenomas of salivary gland origin: intrasurgical rupture, histopathologic features, and pseudopodia. Cancer 1998;82:617-20. Crossref

8. Cerulli G, Renzi G, Perugini M, Becelli R. Differential diagnosis between adenoid cystic carcinoma and pleomorphic adenoma of the minor salivary glands of palate. J Craniofac Surg 2004;15:1056-60. Crossref

9. van Heerden WF, Raubenheimer EJ. Intraoral salivary gland neoplasms: a retrospective study of seventy cases in an African population. Oral Surg Oral Med Oral Pathol 1991;71:579-82.

10. Harada $\mathrm{H}$. Histomorphological investigation regarding to malignant transformation of pleomorphic adenoma (so-called malignant mixed tumor) of the salivary gland origin: special reference to carcinosarcoma. Kurume Med J 2000;47:307-23. Crossref

11. Torske K. Benign neoplasms of the salivary glands. In: Thompson LDR, Goldblum JR. eds. Head and Neck Pathology (Foundations of Diagnostic Pathology). 1st ed. Philadelphia, PA: Elsevier's Health Sciences, Churchill Livingstone 2006:295-320. 